\title{
Likelihood of 'falling through the net' relates to contemporary prevalence of gestational diabetes
}

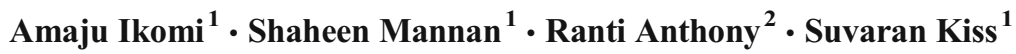

Received: 19 June 2015 / Accepted: 21 July 2015 /Published online: 8 August 2015

(C) Springer-Verlag Berlin Heidelberg 2015

Keywords Diabetes · Diagnosis · Gestational · Guideline · Macrosomia · Population · Prediction · Pregnancy ·

Prevalence $\cdot$ Screening

\section{Abbreviations \\ GDM Gestational diabetes mellitus \\ IADPSG International Association of the Diabetes and Pregnancy Study Groups \\ NICE National Institute for Health and Care Excellence}

To the Editor: The study published in Diabetologia by Meek et al successfully highlights the problem of 'falling through the net' associated with implementation of the UK National Institute for Health and Care Excellence (NICE) 2015 glucose thresholds for diagnosing gestational diabetes mellitus (GDM) $[1,2]$. The authors are to be commended for bringing their data to light so soon after publication of the NICE 2015 guidelines but we would like to take this opportunity to pose some questions and provide further comment.

Our first query relates to an omission in not reporting the number of glucose readings within each OGTT result during the study period. Meek et al clearly state that at that time the

Amaju Ikomi

Amaju.Ikomi@btuh.nhs.uk

1 Department of Obstetrics and Gynaecology, Basildon and Thurrock University Hospitals NHS Foundation Trust, Nethermayne, Basildon, Essex SS16 5NL, UK

2 Department of Obstetrics and Gynaecology, Southend University Hospital NHS Foundation Trust, Prittlewell Chase, Westcliff-on-Sea, Essex, UK
WHO 1999 criteria (fasting and $2 \mathrm{~h}$ values) were used for diagnosing GDM [3], but the results imply $1 \mathrm{~h}$ values were also measured. We presume it was their practice to measure but ignore $1 \mathrm{~h}$ values, and clarification on this matter would be most helpful.

We are also interested to know the reasoning behind their choice of study period (2004-2008). Seemingly, one advantage is that it dates back to when neither the International Association of the Diabetes and Pregnancy Study Groups (IADPSG) standards [4] nor the NICE 2015 standards [2] existed, thus negating any possibility of knowledge of these being judged to be a confounding factor. A counter argument relates to the fact that 2004 was 11 years ago, and this detracts from the generalisability of the study to discussions about contemporary prevalence of GDM. The authors have made statements relating to the low prevalence in their population but in the discussion have not considered the likely changes in their population since the study period. This is crucial, as a rising prevalence of any condition increases the positive predictive value of relevant diagnostic tests (in this case, all diagnostic criteria for GDM) and is thus likely to reduce any differences in diagnostic effectiveness between different tests [5]. Therefore, in the absence of a static prevalence rate, it is unlikely that the numbers 'falling through the net' in 2004-2008 will accurately extrapolate to 2015. In keeping with worldwide experience, we postulate that the prevalence of GDM in Cambridgeshire has risen since the study period, as a result of increasing obesity, maternal age and ethnic diversity. Supporting this assertion, data available from Yorkshire and Humber Public Health Observatory (YHPHO) Diabetes Community Health Profiles show that the Asian/black population in Cambridgeshire gradually increased from around $1 \%$ in 2009 to $3.3 \%$ in 2012 [6].

Our experience in south west Essex is a case in point. We, too, used the WHO 1999 criteria [3] at around the same time, 
but in 2006 we also adopted the American Diabetes Association (ADA) $1 \mathrm{~h}$ threshold of $>9.9 \mathrm{mmol} / \mathrm{l}$ (fortuitously the same as the subsequent IADPSG threshold) [7]. In 2012 we retrospectively assessed the potential impact of implementation of the new IADPSG thresholds [4] on our practice by analysing the results and outcomes of 2,905 antenatal OGTTs performed on at-risk women (according to NICE 2008 guidelines [8]) between 2009 and 2011. On applying IADPSG criteria we found a $30 \%$ macrosomia rate $(>4 \mathrm{~kg})$ in 129 women who retrospectively had been 'missed' (IADPSG positive, WHO/ADA negative) and therefore had not been treated (R. Anthony, A. Ikomi, R. Khan, P. Angala, S. Kiss, unpublished data). On the basis of these findings we proceeded to implement the IADPSG thresholds in February 2013.

Subsequent evaluation of the effects of prospective application of IADPSG criteria to 903 antenatal OGTT results surprisingly revealed a changed diagnostic status in only $3.1 \%$ of patients as opposed to the predicted 7.4\% [9]. Further analysis revealed that the difference in GDM incidence (rate of abnormal OGTT results) between the IADPSG and WHO/ADA criteria had gradually reduced from $3.4 \%$ in 2009 to $1.3 \%$ in 2011 and further down to $1.1 \%$ by 2013 . This trend was associated with a year-on-year increase in our number of GDM cases, reflecting our earlier assertions about how prevalence affects the diagnostic effectiveness of a test. Reassuringly we also witnessed a significant reversal in clinical outcomes, with only a $10.5 \%$ macrosomia rate in the women who would have previously been missed (IADPSG positive, WHO/ADA negative) but were now treated.

Having already implemented IADPSG criteria in south west Essex, the obvious conclusion based on the study by Meek et al would be to judge a change to NICE 2015 criteria as a retrograde step. However, our journey thus far has embedded our recognition of the importance of up-to-date contextual data in addressing inherent changes in population demographics. For this reason, our final decision on this matter will be delayed until the completion of an ongoing analysis of our own OGTT results in 2014-2015. We urge other UK units to do the same.

Acknowledgements We thank T. Everitt (Clinical Biochemistry, Basildon and Thurrock University Hospitals NHS Foundation trust UK) for his contribution to data extraction.
Duality of interest The authors declare that there is no duality of interest associated with this manuscript.

Contribution statement All authors were responsible for drafting the article and revising it critically for important intellectual content. All authors approved the version to be published.

\section{References}

1. Meek CL, Lewis BL, Patient C, Murphy HR, Simmons D (2015) Diagnosis of gestational diabetes mellitus: falling through the net. Diabetologia. doi:10.1007/s00125-015-3647-z

2. National Institute for Health and Care Excellence (NICE) (2015). Diabetes in pregnancy: management of diabetes and its complications from preconception to the postnatal period. Clinical guideline NG3 (2015). Available from www.nice.org.uk/guidance/ng3/ resources/diabetes-in-pregnancy-management-of-diabetes-anditscomplications-from preconception-to-the-postnatal-period 51038446021, accessed 16 June 2015

3. World Health Organisation (1999) Definition, diagnosis and classification of diabetes mellitus and its complications. Part 1: diagnosis and classification of diabetes mellitus. WHO, Geneva, http:// whqlibdoc.who.int/hq/1999/WHO_NCD_NCS_99.2.pdf?ua=1, accessed 16 June 2015

4. Metzger BE, Gabbe SG, Persson B et al (2010) International Association of Diabetes and Pregnancy Study Groups recommendations on the diagnosis and classification of hyperglycemia in pregnancy. Diabetes Care 33:676-682

5. Lalkhen AG, McCluskey A (2008) Clinical tests: sensitivity and specificity. Continuing education in anaesthesia. Criti Care Pain 8: 221-223

6. Yorkshire and Humber Public Health Observatory (2013) Diabetes community health profiles. Available from www.yhpho.org.uk/ diabetescommunityhealthprofiles/default.aspx, accessed 15 June 2015

7. American Diabetes Association (2001) Clinical practice recommendations 2001: gestational diabetes mellitus. Diabetes Care 24(Suppl 1):S77-S79

8. National Institute for Health and Care Excellence (NICE) (2008) Diabetes in pregnancy: management of diabetes and its complications from preconception to the postnatal period. Clinical guideline 63 (2008). Available from www.nice.org.uk/guidance/cg63/ resources/guidance-diabetes-in-pregnancy-management-ofdiabetes-and-its-complications-from-preconception-to-thepostnatal-period-pdf, accessed 16 June 2015

9. Mannan S, Ikomi A, Khan R, Kiss S (2014) Implementation of the new international guidelines in a UK university hospital: predicted versus actual consequences. Brit J Obstet Gynaecol 121 (Suppl s2): 151 (Abstract) 